\title{
Molecular mechanisms of reversing neural degeneration by retinoic acid, a major derivative of vitamin $\mathrm{A}$
}

\author{
L.T. Ranaweera, S. Rajapakse and S.D.S.S. Sooriyapathirana* \\ Department of Molecular Biology and Biotechnology, Faculty of Science, University of Peradeniya, \\ Peradeniya, Sri Lanka
}

Received: 07/04/2017; Accepted: 27/07/2017

\begin{abstract}
For the past hundred years since the discovery of vitamin A, the field of research associated with retinoids has been well evolved due to advances in molecular biology, chemistry, biochemistry and medicine. Vitamin A is an essential component in diet. Major derivatives of vitamin A such as retinol, retinaldehydes and retinoic acid are collectively considered as retinoids. Deficit of Vitamin A has a direct correlation with disease development in our body emphasizing the importance of retinol. Retinoic Acid is proclaimed as powerful mitogen acting in our body since the developmental embryonic stages where it is associated with many organ systems in body carrying out different functionalities. Retinoids carry out many functions of nervous systems. This review is mainly focused on contribution of Retinoic acid towards reversing the process of neural degeneration in pathological conditions achieved by neurodegenerative diseases and tumor inducing situations. Retinoids can act on neurons carrying morphogenesis of nerves by promoting stem cell differentiation. Activation of phospholipase A2 pathway can promote neural differentiation. Also by inactivating human Inhibitor of DNA binding 2 gene, retinols can suppress stem cell proliferation and initiate morphogenesis. This gene inactivation can be also used as a therapy to prevent malignant cell proliferation leading to tumors. Anti amyloidogenic activity is discussed in this review locates a significant importance in reversing neural degenerating process in diseased conditions. Moreover, Reactive Oxygen Species accumulation can be suppressed by Retinoic Acid where it can promote cell survival during pathological constrains. The revision of literature is carried out in depth revealing Retinoic Acid related putative drug target mechanisms, where we can use Retinoic Acid as a novel therapeutic drug in neurodegenerative diseases.
\end{abstract}

Keywords: Anti amyloidogenic activity, Human Inhibitor of DNA binding 2 gene phospholipase A2, Reactive Oxygen Species, Vitamin A, Retinoids.

\section{INTRODUCTION}

Vitamin A is known to be one of the most important components in the diet. Vitamin A and its derivatives carry out many morphological and physiological functions in animal bodies. Thus, it has been one of the widely studied molecule over the past century. Back in 1913, it was proclaimed that a lipid soluble molecule contained in the diet of rats encouraged their growth and was later named as Vitamin A or retinol (McCollum and Davis, 1913). Studies carried out by McCollum and Davis in early $19^{\text {th }}$ century revealed that lack of a certain substance in diet caused night blindness (McCollum and Davis, 1913). Later studies claimed that "Fat soluble A" (synonym to vitamin A) plays an important role in preventing night blindness and xeropthalmia (Goodman, 1984). Since 1930, developments in chemistry, cell biology and molecular biology have explored many pathways related to retinol and its precursors and scientists have successfully synthesized these compounds chemically (Isler $e t$ al., 1947). Another landmark in this area of study was the discovery of retinol binding proteins in animal tissues. Retinol binding protein was first discovered in 1968 with a single polypeptide chain which is responsible for transporting retinol in plasma (Kanai et al., 1968). This aided in understanding retinol transport to many organ systems including most vital parts of our body such as brain. Except in plasma, two types for retinoic binding proteins found in human tissues (Chytil, 1982). They are slightly different from each other in immunological properties and ligand binding specificities (Chytil and Ong, 1978). Scientists have characterized retinol binding proteins in tissues such as liver of rats, dogs and humans, bovine retina and rat testis (Chytil, 1982; Chytil and Ong, 1978; Saari et al., 1982). 
Vitamin A is an essential vitamin in our diet as it cannot be synthesized by de novo pathway. It must be taken up as a dietary component or as a stored vitamin source (Harrison, 2012). Hence, the study of biosynthesis, absorption, metabolism and transport of retinoid is very important. Natural reservoirs of vitamin $A$ include $\beta$ carotene pigments in many plants which are then transformed to retinol in mucosa of intestine. They are then re-esterified and transported inside vesicular compartments by the circulatory system (Goodman and Olson, 1969). Storage of vitamin A derivatives in our body is mainly carried out by the liver which is known to have reserves of other vitamins taken up from various dietary substances (Goodman, 1984). Fat storage cells in the liver is the most responsible hepatic cell type in storing vitamins and also aids in maintaining steady vitamin contents in blood plasma (MCLaren, 1981). Hepatic parenchyma cells secrete plasma retinol binding proteins that aid in active uptake of retinal - esters. These cells are one of the major cell type responsible for metabolism and storage of retinal esters (Poole et al., 1975).

Retinoids effectively take part in cellular differentiation and many in vitro studies have been undertaken since 1925 to understand underlying molecular mechanisms (Goodman, 1984). Except model animal testing, organ and cell culture studies have been undertaken to understand the ramifications of retinoids on cell differentiation (Fell and Mellanby, 1953). Fell and Mellanby (1953) made attempts by treating chick epidermal tissue in cell culture system with various doses of retinol acetate and observed that it could induce a drastic phenotypic change on the functionality of the tissue, as keratinized epidermis differentiated into mucus producing cell lines (Fell and Mellanby, 1953). Even though they were able to identify phenotypic effects, underlying molecular cross talking cassettes have not been well understood during that time.

Understanding cell signaling pathways and effector molecules involved in retinoids are important aspects in modern therapeutics. Retinols and their derivatives are involved in each and every organ system carrying out major effector functions. Alteration of retinoids in disease pathogenesis is also very peculiar to understand. Many molecular targets of therapeutics can be identified by scrutinizing intrinsic causes (Guo et al., 2015; Greena et al., 2016). Retinoid isomers inside cells are known to carry out gene activation mechanisms and transcription regulation. They are also involved in the production and regulation of effector molecules which carry out major functions in cell survival, pathogenic effects as well as in structural culminations (Greena et al., 2016).

Probing into neurobiology and underlying signaling pathways regarding neural regeneration, stem cell proliferation and cell differentiation is one of the most promising area of research (Wuarin and Sidell, 1991; Wuarin et al., 1990; Zhelyaznik et al., 2003). However, complete molecular cross talking mechanisms remain ambiguous. It is vital to understand the cell biology of neuro degenerative diseases and tissue malignance in order to design appropriate therapeutics. Intrinsic properties causing diseases such as uncontrolled transcription (Ruzinova and Benezra, 2003; Lasorella and Iavarone, 2006), Reactive Oxidative Species (ROS) accumulation (Eichele, 1997) and synthesis of molecules leading to apoptosis (Amtul et al., 2012) have been studied. In addition, extrinsic properties such as physical constrains, stress factors (Vogel, 2000) and toxic substances (Eichele, 1997) have also been examined and many approaches to address numerous pathological constraints have been under taken.

An extensive literature survey was carried out in this review covering components and functions entailed in vitamin A metabolism, storage and transport to extra hepatic tissues. A demonstration of retinoid biosynthesis and conversion of inactive forms to active forms of retinoids carrying out signaling is presented here. Retinoic acid (RA) is an important effector molecule and carries out its function in many organ systems. In the nervous system various types of genes can be activated by retinoic acid where it plays a vital role in maintaining the stability and cell integrity. In this review we stress on retinoic acid induced molecular cross talking mechanisms involved in neurodegenerative disease resistance and how that knowledge could be utilized to overcome neuron dysfunction by using RA as a therapeutic strategy. 


\section{METABOLISM AND TRANSPORT OF RETINOIDS}

\section{Vitamin A Metabolism and Hepatic deposition}

Collectively, all vitamin A derivatives are called retinoids (Guo et al., 2015). Retinol is the primary type of retinoid found on the circulatory system (D'Ambrosio et al., 2011; Goodman and Blaner, 1984). It is important to look at retinol biosynthesis to understand vitamin A uptake to the body. The main pathway involved in uptake of retinols and preformed retinol is explained in Figure 01.

\section{Retinoid Transport and Up taking in Extra Hepatic Tissues}

It is critical to understand prime mechanisms underlying retinol transfer into extra hepatic tissues where most of the retinol effector functions are carried out. In circulatory system, different types of retinoids move and bind to various receptor molecules such as chylomicron bound retinal esters (Greena et al., 2016; D'Ambrosio et al., 2011; Goodman and Blaner, 1984). Retinols tether with Retinol Binding Protein (RBP) (Kawaguchi et al., 2007) and further processed into RA (D'Ambrosio et al., 2011). These are the main transport mediators in the plasma performing retinoid transport. There are three main mechanisms involved in the uptake of above mentioned derivatives of retinoids (D'Ambrosio et al., 2011). Chylomicron bound retinal esters are directly transported to the cell by an unknown receptor molecule where cell acquires retinal esters.



Cytoplasm of Enterocyte

Figure 1: Vitamin A metabolic pathway in enterocytes. In the mucosal lumen, processed vitamin A derivatives (proretinoid carotenoids) such as $\beta$ carotene are up taken to the intestinal lining enterocytes through scavenge receptor class B, type I (SR-B1) (Van-Bennekum et al., 2005; During and Harrison, 2007; Lobo et al., 2010) in which cellular $\beta$ carotene undergoes two fates (D'Ambrosio et al., 2011). They can readily convert to retinal via $\beta$-carotene-9', 10'-monooxygenase (BCMO1) (Blaner and Olson, 1994) and get attached to Cellular Retinal Binding Protein (CRBP) type II and remain in the cytoplasm (D'Ambrosio et al., 2011). Pre formed retinols in intestinal lumen can also get in to the enterocytes via a membrane protein called retinyl ester hydrolase and stay bound to CRBP II receptors. Cellular $\beta$-carotene gets associated with cellular triglyceride molecules and forms chylomicrons containing unprocessed retinols. CRBP bound retinal molecules are reduced by the retinal reductase enzyme producing retinols (Goodman and Blaner, 1984). These stable forms can stay in the cytoplasm for a while. Whenever a retinol releasing signal is transduced to enterocytes, it will convert most of the cytoplasmic CRBP bound retinols to retinal esters using lecithin: retinol acyltransferase (LART) and other retinols will convert using diacylglycerol acyltransferase 1 (DGAT 1) (O’Byrne et al., 2005). These retinyl esters get associated with triglyceride lipid molecules and form chylomicron (Greena et al., 2016). Chylomicrons are transported through gut epithelium to lymph duct in which they circulate and the most of excess chylomicron bound retinols are up taken in to liver through a mechanism called sieving (Wisse et al., 1985). Hepatocytes and fat storing cells are the major storage cells of retinoids and they can undergo further medicalization (Greena et al., 2016). 
However, some extra hepatic tissues such as Lipoprotein Lipase (LPL) can convert retinal esters to retinol which can be absorbed in to the cell (Blaner et al., 1994). Retinoic acid bound to albumin is also taken up by extra hepatic tissues by a molecular mechanism which is yet unclear. Retinols bound to holo RBP can get converted to apo RBP through a transmembrane protein called STRA6 (Stimulated by Retinoic Acid 6) (Blaner et al., 1994; Isken et al., 2008). This process involves active uptake of retinols into the extra hepatic tissue. When neurons in the brain are considered, most of the molecules need to penetrate through the blood brain barrier. This is done by transporter molecules which are very important drug target molecules and it is possible to induce them to achieve high amount of retinoid uptake improving brain functions in treating of neuro degenerative diseases.

\section{RETINOIC ACID SIGNALING AND GENE ACTIVATION}

Retinoic acid signaling pathways have been identified in many body tissue types that regulate different genes and control effector molecules. Different molecules associated within these pathways have been target molecules for inducing RA production as a therapeutic drug. Hence, understanding of overall signaling mechanisms involved in RA synthesis and cell signaling pathways in target cells is an essential step in producing therapeutics. A model pathway involved in RA synthesis, signaling pathways and gene activation process is shown in Figure 2.

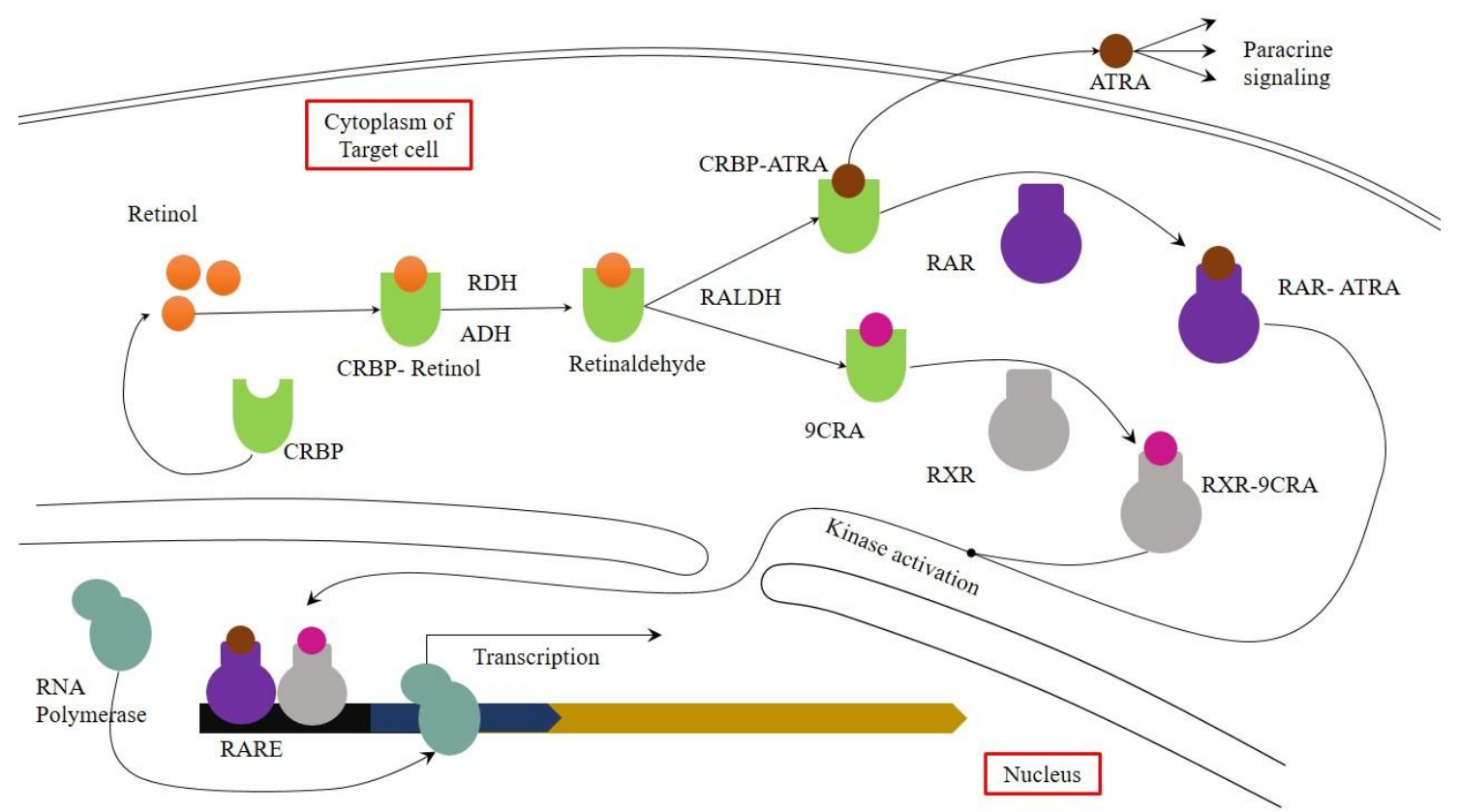

Figure 2: Overview of cellular retinoid metabolism and RA dependent cell signaling pathway. Cellular retinoids up taken from the blood plasma are found to be bound to Cellular Retinoic Binding Proteins (CRBP) type proteins (D'Ambrosio et al., 2011). Two enzymes are involved in converting CRBP bound retinols to retinaldehydes; Alcohol Dehydrogenase (ADH) and Retinol Dehydrogenase (RDH). Cellular production of All-Trance Retinoic acids (ATRA) and 9-cis-Retinoic Acids (9CRA) is escalated by Retinaldihyde Dehydrogenase (RALDH) class molecules such as RALDH I, II, III (Conaway et al., 2013). The prime fate of processed RA is acting on effector genes. Hence they bind to Retinoic acid receptors (RAR, RXR) found on cytoplasm and move to nucleus through Nuclear Pore Complex (NPC) and get phosphorylated by kinase enzyme to form an active receptor molecule. At the active state, they eliminate repressor complexes found on promoters of target genes and get attached to Retinoic acid Receptor Elements (RARE) where they enhance the utilization of transcription factors on promoters and carry out transcription (Perissi et al., 2010). 
There are two types of RA receptor molecules i.e Retinoic Acid Receptor x (RARx) and Retinoic Acid Receptor s (RXRs). They act as intracellular receptor molecules which carry out ligand bound transcription activation and activate many RA effector genes regulating cellular proliferation and differentiation (Glass and Rosenfeld, 2000; Aranda and Pascual, 2001). The RAR receptors found in the body consist of three isomers produced by alternative splicing $(\operatorname{RAR} \alpha, \beta, \gamma)$ and carry out different functions. $\operatorname{RAR} \beta$ is found to be a promising target molecule for tumors as well as in cell proliferation and differentiation, post natal maintenance and some dermatology diseases (Tasi et al., 2009; Christov, 2009; Petty et al., 2005). The RAR and RXR (RARx) get tangled to form RAR-RXR heterodimers bound to Retinoic Acid Receptor Elements (RAREs) that are inactivated by nuclear-receptor-co-receptor complexes (NCoR), which inhibit the binding of transcriptional activators to the promoter site (Perissi et al., 2010).

Cellular RA molecules produced have three main fates. They can undergo cell signaling pathways activating genes, get transferred outside the cell and comprehend in paracrine signaling or are broken down by Cytochrome P450 26 (CPY26) (Abu-Abed et al., 2001). Retinoic acid paracrine signaling is very important in embryonic development where cell to cell cross talking mechanisms carry out morphogenetic functions such as differentiation of pluripotent stem cells (Molotkov et al., 2006; Duester, 2008).

\section{EFFECTS OF RETINOIC ACID IN OTHER ORGAN SYSTEMS}

From early embryonic stages, RA dependent signaling shapes the body morphology as well as functionality. In addition, RA can be used against disease pathogenicity. Natural vitamin A deficit directly acts on nervous system and immune system causing adverse effects (Guo et al., 2015; Dawson et al., 2006; Imdad et al., 2010; Dupe et al., 2003). Further, experiments using transgenic model animals containing knockout RA utilizing genes have revealed that some phenotypes are lethal (Greena et al., 2016; Molotkov et al., 2002) while some model animals had disease pathogenic conditions. For example, Raldha-2- transgenic mouse lines who cannot utilize all-trance retinoic acid or 9-cis retinoic acid are found to be a lethal phenotype (Guo et al., 2015). Therefore, RA is one of most important effector molecule in shaping tissue and organ systems.

\section{Retinoic acid on Adult Vertebrate Appendage Regeneration}

Epimorphic regeneration is a well-known phenomenon among male teleosts fish and among many amphibians (Mathew et al., 2009; Blum and Begemann, 2012; Zakany et al., 2004). The RA signaling has been well studied in fin regeneration of zebrafish (Blum and Begemann, 2012). Gene aldhla-2 codes for the enzyme responsible for synthesizing RA and is found to be regulated in adult zebrafish on regenerating caudal fins 24 hours after amputation (hpa) (Mathew et al., 2009 ). In terms of expression, phasing of aldhla-2 occurs with about six hpa where the transcripts are found in mesenchymal cells, one segment proximal to the plane of amputation. Blastema formation is impeded when RA signaling pathways are suppressed. Retinoic acid molecular signaling pathways govern the blastema formation at the early stages where fin ray mesenchymal cells get proliferated and move to amputation sites form blastema (Blum and Begemann, 2012). Mitogen activity of RA signaling pathway may have a correspondence with stem cell proliferation. Induction of stem cells in the amputated plane may move to the wound where the wound healing process takes place. The RA signaling also cross talks with apoptotic signaling by B cell lymphoma 2 (bcl2) up regulation where it mediates pro survival of blastema, till it matures (Blum and Begemann, 2012). Hostile environment can be lethal to proliferating blastema cells and Programmed Cell Death (PCD) can be induced. A similar mechanism is proposed in zebrafish heart regeneration which involves elevated expression of aldhla-2 in epicardium and endocardium where cell division and proliferation are promoted (Kikuchi et al., 2011).

\section{Role of Retinoic Acid in Immunity}

Dietary vitamin A is recognized as an essential factor for the maintenance of immunity (Ross, 2012). $\beta$ carotene and vitamin $A$ are known to act against infections and they were identified as "anti-infective agents" in late $19^{\text {th }}$ century (Green and Mellanby, 1928; Green and 
Mellanby, 1930). In different studies performed using animal models to verify the relationship between RA and lymphocyte production, abnormalities have been observed in the production of antibodies (low production of $\operatorname{IgA}$ and elevated amounts of IgG) (Stephensen et al., 1996; Twining et al., 1997; Zhao and Ross, 1995). There is a direct correlation between Alltrance retinoic acids (ATRA) and B lymphocyte mediated immunity. The RAR-ATRA controlled gene transcription allows immunoglobulin accumulation in B lymphocytes (Chen and Ross, 2005). The B cell proliferation and activation by up regulating co-receptor molecules is aided by similar molecules (Ma et al., 2005). Further, immunological diversity is controlled by RARATRA receptor molecules by up regulating proteins needed for phenomena such as class switching and somatic hyper mutation (Cattoretti et al., 2006) while RAR-ATRA also helps in B cell maturation (Chen and Ross, 2007). In addition, RA paracrine signaling mechanisms allow cellular cross talking among leukocytes to overcome infectious conditions (Guo et al., 2015).

\section{Maintenance of Bones by Retinoic Acid}

Bone morphogenesis and cellular differentiation are carried out by many effector molecules, governed by retinoic acid (Shenga et al., 2010). Bone Morphogenic Proteins (BMP) which are under the Super family of Transforming Growth Factor $\beta(\mathrm{TFG}-\beta)$ are primarily responsible for carrying out molecular cross talking with other pathways which are essential for bone morphogenesis (Chen and Ross, 2007). Essential molecular communicating mechanism involves Smad1 protein and BMP proteins; which are prime molecules sustaining bone morphogenesis (Feng and Derynck, 2005; Wang et al., 2011). Uncontrolled differentiation involves in disease and abnormal situations where RA come to the play. The RA is known to carry out a major function in regulating these effector molecules via suppressing Smad1 pathway, thereby causing bone morphogenesis (Chen and Ross, 2007). Retinoic acid also induces proliferation of osteoclasts from myeloid progenitor cells carrying out maintenance of osteoclasts till maturation (Greena et al., 2016).

\section{REVERSING NEURAL DEGENARAION BY RETINOIC ACID}

\section{Regulation of Inhibitor of DNA binding 2 gene Expression by retinoic acid}

Inhibitor of DNA binding 2 (ID2) (Ruzinova and Benezra, 2003) plays an important role in tissue development, acting as a transcription factor that promote cell proliferation, but discourages differentiation (Annibali et al., 2012). In development of neural tissues, ID2 maintains a high level of pluripotent neural stem cells while it inhibits neurogenesis by inhibiting differentiation (Henke et al., 2008; Martinsen and Bronner-Fraser, 1998; Bai et al., 2007). When cell accumulates low levels ID2, it promotes neural differentiation collectively with Neural Growth Factor (NGF) (Henke et al., 2008; Martinsen and Bronner-Fraser, 1998; Bai et al., 2007; Zhang et al., 2010). MicroRNAs can act on genes at transcriptional levels inhibiting transcription mechanisms by directly binding to genes (Bartel, 2004; Kasinski and Slack, 2011). MicroRNAs are used as a therapeutic agent in tumors as they suppress tumor inducing genes (Kasinski and Slack, 2011). At this regulation level, miR-9 and miR-103 are responsible for the regulation of cellular ID2 levels (Annibali et al., 2012). Retinoic acid is a key effector molecule in up regulating the above micro RNAs (Laneve et al., 2007). Figure 3 shows detailed mechanisms involved in this process.

At normal conditions ID2 remains active in neuroblastoma based neural precursor cells to accrue the stem cells (Iavarone and Lasorella, 2006; Martinsen and Bronner-Fraser, 1998). The ID2 binds to $\mathrm{E}$ protein which gets hindered to bind Helix-Loop-Helix (HLH) protein heterodimers. They binds to E-box regulated genes such as Growth Associated Protein 43 (GAP43) gene and carry out growth and differentiation (Lo'pez-Carballo et al., 2002). With the treatment of RA due to diminished ID2, suppression of the E-box element stops and HLH heterodimer binds to $\mathrm{E}$ box proteins and carry out transcription (Annibali et al., 2012). Suppressing RA to induce the activity of ID2 genes can result in producing neural stem cell pools in vitro which can be used in stem cell therapy for neurodegenerative diseases such as Parkinson disease (PD). However, uncontrolled transcription of ID2 will result in tumor situations (Vandeputte et al., 2002; Perk et al., 2005). 


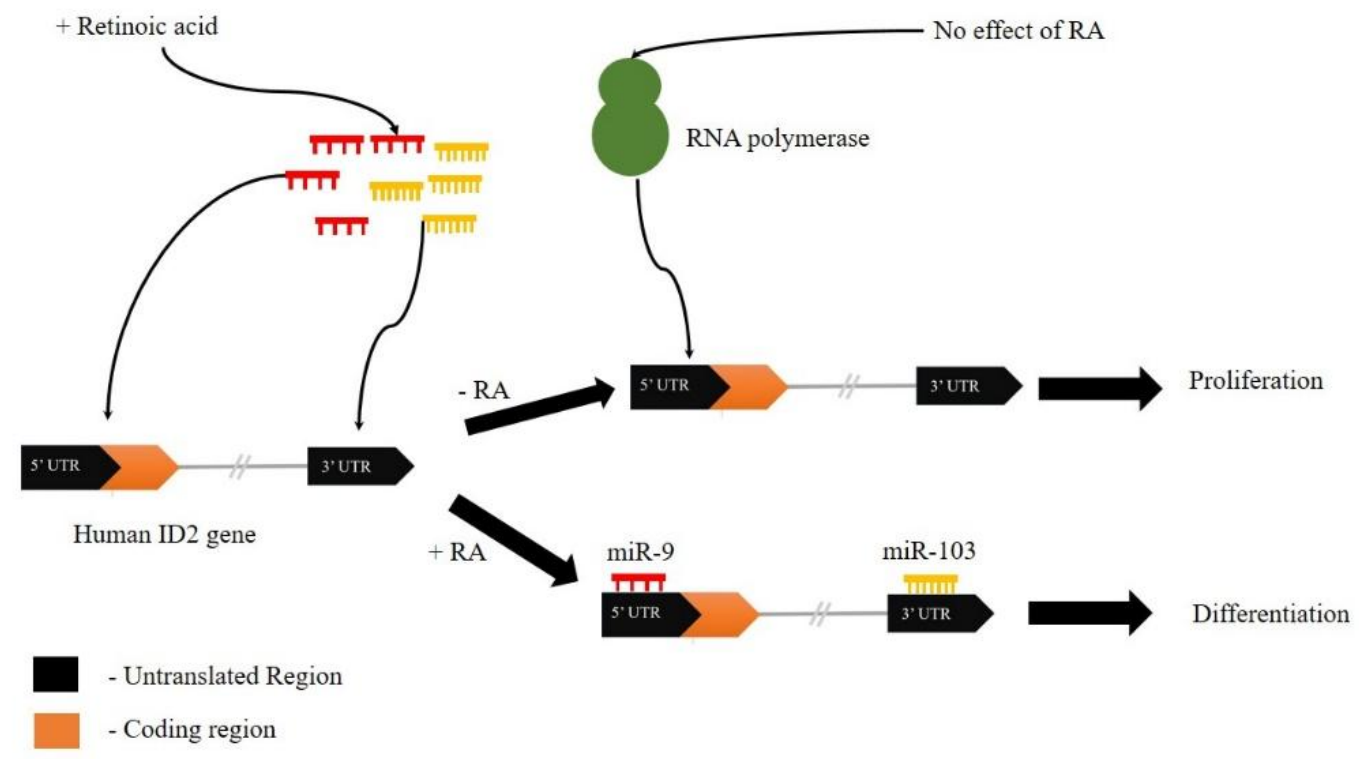

Figure 3: The RA induced neural differentiation by arresting transcription of Human ID2 gene through MicroRNAs. Human Inhibitor of DNA binding 2 (ID2) gene is responsible for the production of Inhibitor of DNA binding 2 protein and carry out different cellular mechanisms which promote proliferation, especially in neuroblastoma. In the presence of RA, it promotes the production of MicroRNA molecules; miR-9 and miR-103. Those microRNA molecules contain highly homologues sequences in untranslated regions (UTR) of Human ID2 gene, where they bind and prevent transcription. The miR-9 binds downstream region of 5' UTR region and miR - 103 binds UTR region of leader sequence of human ID2 gene, and tightly regulates transcription. Subsequently cells carry out differentiation using these molecular mechanisms together with NGF factors (Annibali et al., 2012).

Transcription of miR9 and miR103 are only carried out in neural tissues (Maruyama et al., 1999; Schoenherr and Anderson, 1995). Gene, encodes for miR9 contains miR9 1,-2 which are induced by RA; but miR9 -3 loci does not respond to RA (Laneve et al., 2010). However, expression of miR103 is ubiquitous (Annibali et al., 2012). Promotion of neural differentiation is important in stem cell treatment where differentiation process is actively controlled. However, differentiation in to specific neurons has not yet been clearly understood. In producing therapies for diseases like Parkinson disease where dopaminergic neurons degenerate, it is important to identify the clear molecular mechanisms and target molecules that can be used to induce the differentiation of dopaminergic neuron reservoirs. The ID2 inhibition by miRNA may be a useful asset in such efforts.

\section{Retinoic Acids in Removing Oxidative Stress}

Oxidative stress by accumulation of Reactive Oxidative Species (ROS) causes many neurodegenerative diseases; mainly Alzheimer's disease (AD), which is the most abundant neurodegenerative disease in the world (Lee et al., 2009; Smith, 1998; Sonnen et al., 2009; Smith, 2006; Kadigamuwa et al., 2015). Risk of AD gets higher with the age (Smith, 1998). Even though primary causes have not yet been understood, one of the candidate cause identified for neuro degeneration is oxidative stress by which accumulation of reactive oxygen species (ROS) (Smith, 1998; Kadigamuwa et al., 2015). The RA derived therapeutics for AD mainly target pre mature oxidative stresses (Sonnen et al., 2009; Smith, 2006). Parkinson diseases is the second most common neurodegenerative disease in the world, mainly caused by degeneration of dopaminergic neurons that are involved in mortar activity (Kadigamuwa et al., 2015). Even though major causes for PD remain ambiguous, many cytotoxic compounds specifically act on dopaminergic neurons have been identified. One of the cytotoxic compound is MMP+ which can readily penetrate through blood brain barrier and inhibit mitochondrial electron transport chain complex 1, causing accumulation of ROS (Kadigamuwa et al., 2015). Newly identified toxin 2'2 cyanine shows higher toxicity compared with MMP+ which also gets 
accumulated in mitochondria. This also leads to accumulation of ROS species in the brain (Kadigamuwa et al., 2015). The ROS can actively interact with many pathways yielding diminutive functionalities (Jeffrey et al., 2006) and leads to induction of programmed cell death in neural tissues which results in high degree of neural degeneration (Lee et al., 2009).

Retinoic acid derived therapeutics for AD mainly target pre mature oxidative stresses (Sonnen et al., 2009). Vitamin A and derivatives promise to reduce the oxidative stress in the brain where dietary intake of vitamin $\mathrm{A}$, vitamin $\mathrm{B}$, and $\beta$ carotene, thereby drastically reduces the risk for getting AD (Sonnen et al., 2009; Smith, 2006). Cytoplasmic concentration of RA carries out anti oxidation effects vividly where diminutive amounts of RA function as an antioxidant of which, high concentrations show pro-oxidant effects (Zanotto- Filho et al., 2008). There are several molecular events taking place in degrading ROS accumulated in neural tissues. Staurosporium is well understood molecule which can actively degrade levels of dismutase enzyme ultimately leading to accumulation of ROS species (Kiningham et al., 2008) as shown in Figure 4.

The SOD-1 and 2 act as free radical antioxidants where they bind to different cofactors (SOD-1 binds to $\mathrm{Zn}$ and $\mathrm{Cu}$ and SOD-2 binds to MN) (Rahman, 2007). The apoptotic inducing signal is known to be a suppressor of glutathione where depleted glutathione will stimulate apoptosis by activating the transporter A dependent cascade reaction (Mytilineou et al., 2002), subsequently producing Amyloid $\beta$ (A $\beta$ ). This phenomenon will be discussed in detail under the section on suppression of amyloid beta by retinoic acid (4.3). Glutathione suppression is widely seen in degeneration of dopaminergic neurons in PD (Nalivaeva et al., 2012a) and SOD suppression is a common phenomenon in $\mathrm{AD}$ (Lee et al., 2009 ). Therefore, retinoic acid could be used as a promising therapeutic drug for most abundant neurodegenerative diseases.

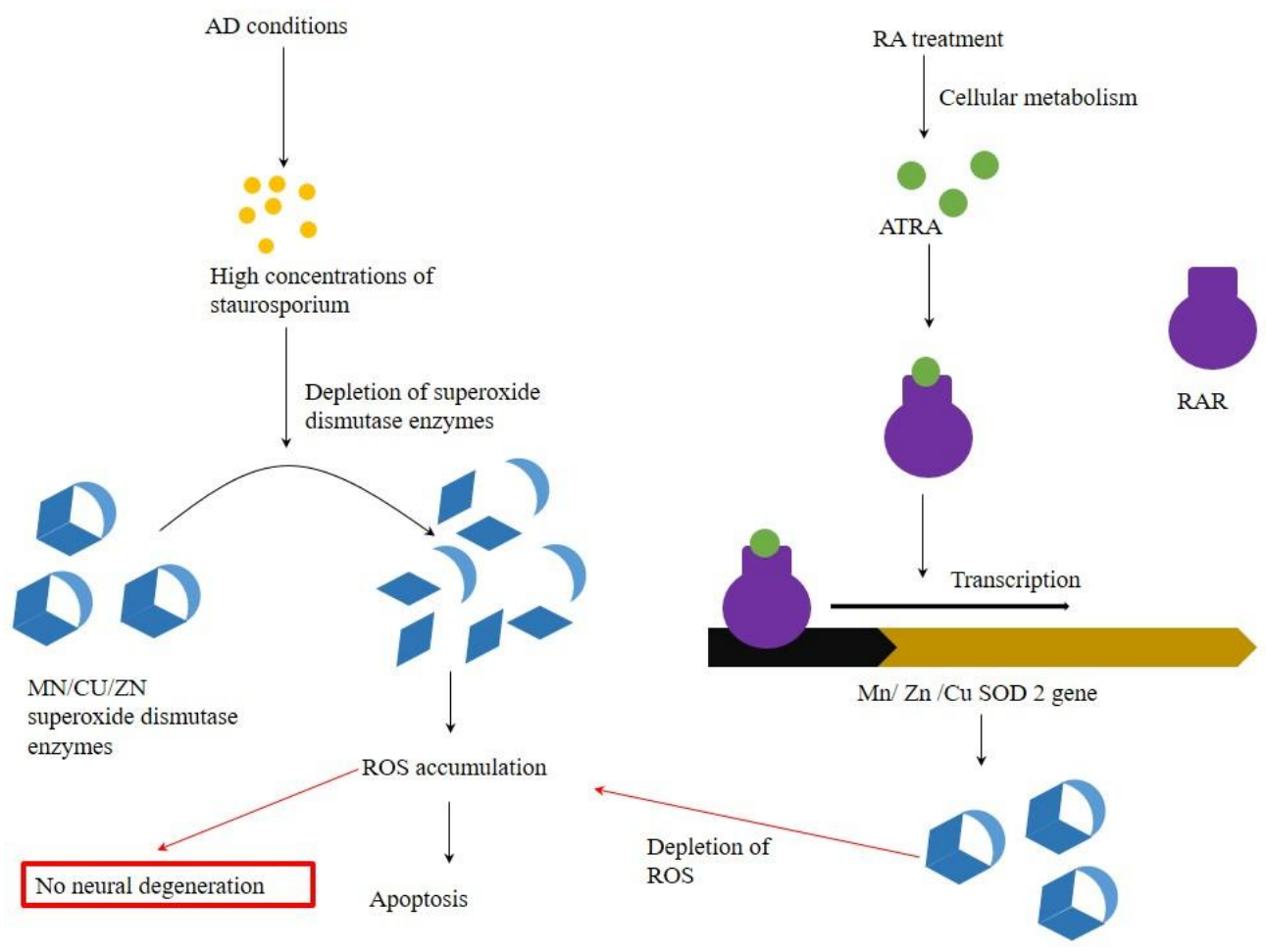

Figure 4: The Reactive Oxidative Species induced RA signaling. Due to Alzheimer's disease pathogenic conditions, cells undergo accumulation of high levels of staurosporium (Ahlemery and Krieglsteon, 2000) that can act on neural dismutase enzymes such as $\mathrm{Mn}$ superoxide dismutase (SOD-2), $\mathrm{Zn}$ superoxide dismutase and $\mathrm{Cu}$ superoxide dismutase (SOD-1) (Ahlemery and Krieglsteon, 2000; Ahlemeyer et al., 2001). Upon suppressed functionality of these enzymes cellular reactive oxygen species (ROS) can survive and get accumulated in the cells where they signal apoptotic signal pathway activation, leading the cells to undergo Programmed Cell Death [PCD] (Ahlemery and Krieglsteon, 2000). But when cells are treated with RA, all-trance retinoic acids bound retinoic acid receptors can undergo phosphorylation activation and bind to retinoic acid receptor elements of cellular Superoxide Dismutase genes ( $S O D-2$ and $S O D-1)$ that up regulate transcription of cellular dismutase enzymes (Ahlemeyer et al., 2001). This will result in regulating cellular dismutase enzymes to usual levels which can degrade ROS species and remove the cellular stressed conditions and escalate cell survival (Kiningham et al., 2008). 


\section{Suppression of Amyloid Beta by Retinoic acid}

Amyloid $\beta$ is a small peptide which has a direct connection with neuro degeneration and it is a well-studied oligomer in neurodegenerative diseases (Nalivaeva et al., 2012a; Miners et al., 2011; Nalivaeva et al., 2008; Nalivaeva et al., 2012b; Koryakina et al., 2009; Morishima et al., 2001) even though few good functions of $A \beta$ have been identified such as synaptic transmission (Turner et al., 2003). Elevated amounts of $A \beta$ can result in pathogenic situations (Nalivaeva et al., 2012b; Koryakina et al., 2009; Morishima et al., 2001). Understanding molecular mechanisms coupled with the production of $A \beta$ and $A \beta$ related pathogenesis is really important in deciphering neurodegenerative diseases such as $\mathrm{AD}$. Over the past decade, the major concern for therapeutic drug target has been the reduction of $A \beta$ levels in neurons (Miners et al., 2011; Nalivaeva et al., 2008; Nalivaeva et al., 2012b). The A $\beta$ liberation from the $A \beta$ precursor protein (APP) is tightly regulated as excess $A \beta$ accumulation causes adverse cellular effects, subsequently activating PCD (Nalivaeva et al., 2012a). Few of the major precursor molecules involved in $\mathrm{A} \beta$ production are $\gamma$ and $\beta$ secretase which lead to the accumulation of $\mathrm{A} \beta$ causing cell to apoptosis (Koryakina et al., 2009). One way of inducing apoptosis is by inducing the production of Fas ligand. In the cortex, excess accumulation of Amyloid $\beta$ induces the activation of c-Jun Nterminal kinase (JNK) (Morishima et al., 2001). The JNK kinase then turns on c-Jun transcription factors by phosphorylation. Latter factors binds to promoter regions of genes activating them to produce FAS ligand (Morishima et al., 2001) which can bind to its Fas receptor in cell membrane and activate apoptosis (Waring and Müllbacher, 1999). In addition, production of ROS also has a correlation with $\mathrm{A} \beta$ when mitochondrial cytotoxins have elevated the levels of A $\beta$ (Leuner et al., 2012).

Inheritable components related to late $\mathrm{AD}$ is tightly regulated by RA (Lee et al., 2009). For example, beta site amyloid precursor proteincleaving enzyme (BACE) (Satoh and Kurod, 2000), precursor protein such as A $\beta P P$ (Hung et al., 1992) and the products of presenilin (PS) 1 and 2 genes (Hong et al., 1999). These molecules promote production of high $\mathrm{A} \beta$ levels, hence accommodates neural degeneration. Reduction of neural $A \beta$ levels as a therapy for late $A D$ pathogenesis by restricting above genes has been studied (Lee et al., 2009). Restriction of the above genes will reduce the release of $A \beta$ from $\mathrm{A} \beta \mathrm{PP}$ by discouraging the cleavage.The A1 protein / ATP-binding cassette transporter A1 (ABCA1) is a major regulatory molecule affecting cholesterol flow and it is highly expressed in brain tissues maintaining membrane fluidity (Hong et al., 1999). Previous studies proved that APP towards cleavage amyloidogenic pathway occurs in cholesterol dense areas known as lipid rafts (Wahrle et al., 2002). The APP molecules can be collectively cleaved by $\beta$ secretase and $\gamma$ secretase removing sAPP $\beta$ domain and CT99 domain respectively. Net cleavage of APP will result in removing A $\beta$ peptide from the membrane (Cárdenas-Aguayo et al., 2014). However, a secretase pathway can carry out cleavage yielding SAPP $\alpha$ and CT83 domains of APP (Cárdenas-Aguayo et al., 2014). The ABCA1 can alter membrane fluidity by dissolving lipid raft, which subsequently suppresses the function of $A \beta$ and $\gamma$ secretase and foster non amyloidogenic pathway by $\alpha$ secretase (Fassbender et al., 2001). It is important to understand the genes transcribing for secretase enzymes and mechanisms of gene regulation to develop RA based therapeutics. Some regulatory mechanisms involved in depletion of concentrations of secretase enzymes, governed by ATRA have been identified (Koryakina et al., 2009). Therefore, RA is proven to be an effective molecule in reducing and regulating $A \beta$ levels thus turning down the genes responsible which can also be used as a therapeutic target. However, it is not possible to shut down the whole gene at once as normal $\mathrm{A} \beta$ levels have specific functions in adult neurons (Turner et al., 2003). The cellular $A \beta$ detection mechanisms by RA remains unclear; however in order to produce effective drug targets, it is essential to clarify some of these mechanisms. One of the well understood mechanism in reducing levels of $A \beta$ is through transcription activation of $\mathrm{A} 1$ protein as shown in Figure 5.

\section{Retinoic Acid towards Stem Cell proliferation and Production of Nerves}

Neural degeneration by a disease can have drastic effects on other body tissues as neurons have a paltrier ability to regenerate or to repair (Calza et al., 2003). This has been one of the major short comings of producing drugs to reverse the effects neuro degeneration. When a 
nerve damage occurs in the scar area, new astrocytes and some other cells are proliferated as a wound healing process (Kernie et al., 2001). Nevertheless the degenerated tissue is not replaced as immature nerve cells die before maturation (Arvidsson et al., 2002). Main governing factors for this inability for regeneration can be the hostile microenvironment, stem cell molecular mechanisms and inactive survival mechanisms or the type of lesion (Calza et al., 2003). Novel studies have shown that Neuron Growth Factor (NFG) and RA collectively aid the regulation of neural cell differentiation and juvenescence in the early growth stages of the human body (Bai et al., 2007; Zhang et al., 2010; Holst et al., 1997).

Gene activation of RA towards stem cell differentiation can reverse the effects of neuro degeneration. One of the mechanisms proposed was activation of phospholipase A 2 (PLA2) pathway enabling the differentiation of proliferating stem cells (Lee et al., 2009; Quadro et al., 2005). The PLA2 is activated by phosphorylated ATRA-RAR complex and binds PLA2 gene and transcribe two isomers; $\mathrm{Ca}^{+2}$ independent PLA2 (iPLA) and cyatasolic PLA2 (cPLA2) (Farooqui et al., 2004). The cPLA2 binds to $\mathrm{Ca}^{+2}$ and gets activated (Farooqui et al., 2004; Abe et al., 2003). Both of these molecules actively contribute to the production of arachidonic acid which is a strong effector molecule associated in many pathways (Lee et al., 2009). It produces leukotriene-A4 molecules which are catalytically converted to leukotriene$\mathrm{C} 4$ by leukotriene-C4 synthase (LTC4S) enzyme. Leukotriene-C4 is the main effector molecule that governs stem cell differentiation in this pathway (Farooqui et al., 2004). In terms of in vivo drug targeting to produce correct type of neurons, has not yet been achieved even though many in vitro studies show the effects of neural specific differentiation (Farooqui et al., 2004). The PLA gene activation in pathogenic and nonpathogenic conditions and associated molecular pathways are shown in Figure 6 .

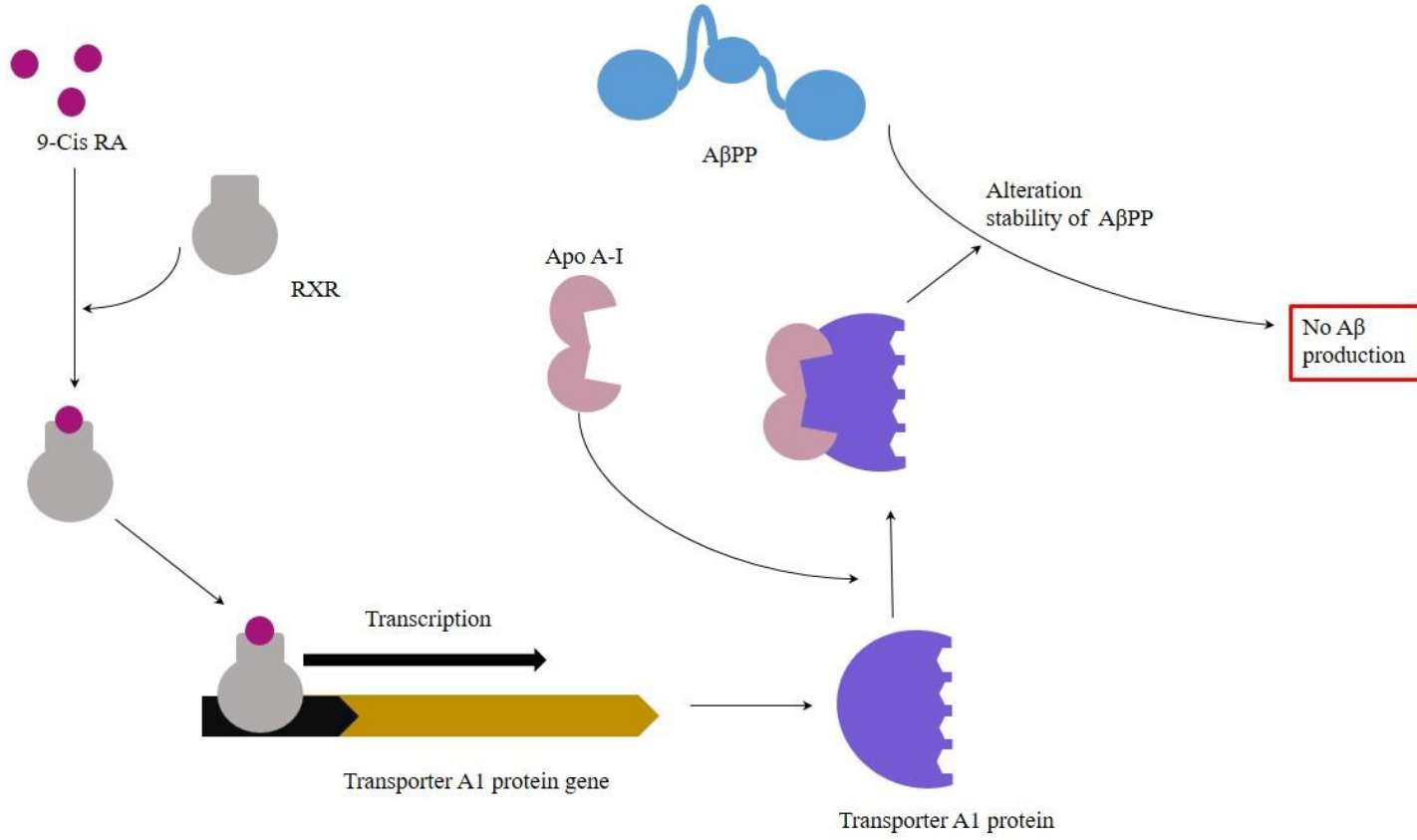

Figure 5: The RA induced Transporter A-1 cascade mediated Amyloid $\beta$ demolition. 9-cis Retinoic Acid produced in the cellular level incorporates with genes responsible for the production of transporter A1 (Lee et al., 2009). The A1 protein involves in a cascade of reactions binding with Apo A-1 ligand in order to act on amyloid $\beta$ precursor protein by destabilizing protein molecules in the C-terminal fragment (Koldamova et al., 2003). This will result in the inhibition of $\beta$ and $\gamma$ secretase, induce $\alpha$ secretase pathway and reduce the production of amyloid $\beta$. 


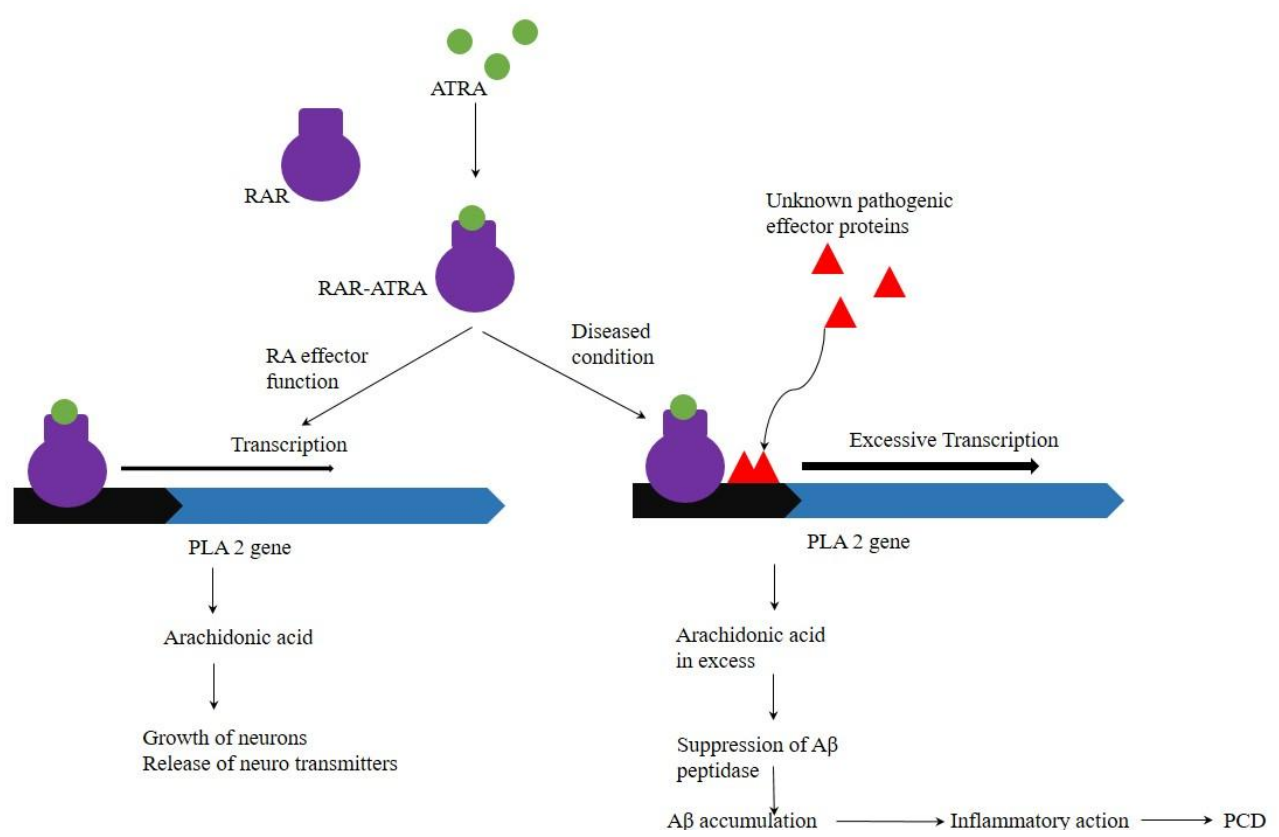

Figure 6: Schematic diagram showing PLA2 signaling pathway and duel role arachidonic acid in both stem cell differentiation and disease development. Excess production of arachidonic acid in diseased situations leads to the production of A $\beta$ causing apoptosis (Lee et al., 2009; Amtul et al., 2012).

Arachidonic acid (AA) is an important molecule in the cellular inflammatory pathway and very important in understanding molecular mechanisms of inflammatory action. Inflammation is a major symptom in many neuro degenerative diseases (Amtul et al., 2012). The AA is a novel study area of PD pathogenesis as it enhances the accumulation of $\mathrm{A} \beta$ by suppressing the peptidase activity of $\mathrm{A} \beta$ peptidase (Amtul et al., 2012).

Post natal maintenance of newly generated nerve cells must be an essential factor in keeping cellular plasticity in the environment. In order to survive in the hostile environments in neural blastema, the cells must arrest apoptosis. Except for the programmed cell death inducing signals produced by pathological conditions, growing stem cells produce apoptotic signals due to harsh environmental conditions (Calza et al., 2003). Retinoic acid is a key player activating antiapoptotic signals by accumulating pro survival molecules in to the cell (Blum and Begemann, 2012). Most of these molecules are cellular anti apoptotic factors which ensures the survival of the growing and differentiating neurons in hostile environments. One such pro survival factor is $\mathrm{Bcl}$ which is activated through RA dependent molecular pathway (Blum and Begemann, 2012). In order to survive in hostile environments, this is an essential factor in post natal maintenance of pluripotent stem cells. Extrinsic stem cell treatment can also be carried out in added

amounts of RA ensuring survival while activating cellular morphogenesis and shaping of the tissue.

\section{CONCLUSION}

Vitamin A is an essential nutrient among dietary components. The vitamin A metabolism in adult animals causes retinol formation which further converts to various isoforms of RA which is responsible for the regeneration mediated body responses such as mitogen activity and body tissue morphogenesis. It also plays a regulatory role by gene activation to balance the levels of various molecules that can exclude pathogenicity due to various intrinsic harmful molecular level destabilizations and carry out post natal maintenance of immature cells.

As RA can act as a powerful mitogen, it can be used as a therapeutic drug to treat the pathogenesis of neurons. The limited capabilities of neural regeneration could be overcome through assigning RA and its isoforms to act as powerful mitogens. The limited amounts of neural stem cell pools can be induced to go through differentiation under the influence of RA. Through administration of RA to the neural stem cells, rapid neural differentiation can be achieved. The RA can be used against accumulation of ROS to fight against disease pathogenesis. The ROS are one of the major molecules that act on the apoptosis of neurons. Up regulation of superoxide dismutase enzyme 
levels can stabilize ROS levels at a "non-threat" rate, thus it can be used as a promising treatment in Parkinson Disease. The A $\beta$ production due to $\beta$ and $\gamma$ secretase is a widely understood phenomenon in $\mathrm{AD}$ that results in neurodegeneration, and RA induced non $\beta$ amyloidogenic pathway can be used to reduce the risk of having AD. Retinoic acid is a strong gene activator that reduces the effects of hostile conditions made by neurodegeneration, and therefore it is possible to use it as a very powerful therapeutic drug for neurodegenerative diseases. However, the current understanding of correct isoforms of RA that need to be delivered and drug delivery systems is insufficient to implement RA as a treatment.

\section{REFERENCES}

Abe, M., Shibata, K., Urata, H., Sakata, N. and Katsuragi, T. (2003). Induction of leukotriene C4 synthase after the differentiation of rat basophilic leukemia cells with retinoic acid and a low dose of actinomycin D and its suppression with methylprednisolone. Journal of Cell Physiology. 196(1): 154-64.

Abu-Abed, S., Dolle, P., Metzger, D., Beckett, B., Chambon, P. and Petkovich, M. (2001). The retinoic acid-metabolizing enzyme, CYP26A1, is essential for normal hindbrain patterning, vertebral identity, and development of posterior structures. Genes \& Development. 15: 226-240.

Ahlemery, B. and Krieglsteon, J. (2000). Inhibition glutathione depletion by retinoic acid and tocopherol protects cultured neurons from staurosporine-induced oxidative stress and apoptosis. Neurochemistry International. 36: 1-5.

Ahlemeyer, B., Bauerbach, E., Plath, M. Steuber, M., Heers, C., Tegtmeier, F. and Krieglstein, J. (2001). Retinoic acid reduces apoptosis and oxidative stress by prevention of SOD protein levels. Free Radical Biology and Medicine. 30: 1067-1077.

Amtul, Z., Uhrig, M., Wang, L., Rozmahel, R.F. and Beyreuther, K. (2012). Detrimental effects of arachidonic acid and its metabolites in cellular and mouse models of Alzheimer's disease: structural insight. Neurobiology of Aging. 33(4): 21-31.

Annibali, D., Gioia, U., Savino, M., Laneve, P., Caffarelli, E. and Nasi1, S. (2012). A New Module in Neural Differentiation Control: Two MicroRNAs Upregulated by Retinoic Acid, miR9 and miR-103, Target the Differentiation Inhibitor ID2. PLOS One. 7(7): 1-12. http://dx.doi.org/10.1371/journal.pone.0040269.

Aranda, A. and Pascual, A. (2001). Nuclear hormone receptors and gene expression. Physiological Reviews. 81: 1269-1304.
Arvidsson, A., Collin, T., Kirik, D., Kokaia, Z. and Lindvall, O. (2002). Neuronal replacement from endogenous precursors in the adult brain after stroke. Nature Medicine. 8: 963-970.

Bai, G., Sheng, N., Xie, Z., Bian, W., Yokota, Y., Benezra, R., Kageyama, R., Guillemot, F. and Jing, N. (2007). Id sustains Hes1 expression to inhibit precocious neurogenesis by releasing negative autoregulation of Hes1. Developmental. Cell 13: 283-297.

Bartel, D.P. (2004) MicroRNAs: genomics, biogenesis, mechanism, and function. Cell. 116: 281-297.

Blaner, W.S. and Olson, J.A. (1994). Retinol and retinoic acid metabolism. In Sporn, MB, Roberts $\mathrm{AB}$, Goodman, DS, eds. The Retinoids. Academic Press, New York, USA .pp 229-256.

Blaner, W.S., Obunike, J.C., Kurlandsky, S.B., alHaideri, M., Piantedosi, R., Deckelbaum, R.J. and Goldberg, I.J. (1994). Lipoprotein lipase hydrolysis of retinyl ester. Possible implications for retinoid uptake by cells. Journal of Biological Chemistry. 269: 16559-16565.

Blum, N. and Begemann, G. (2012). Retinoic acid signaling controls the formation, proliferation and survival of the blastema during adult zebrafish fin Regeneration. Development. 139(1): 107-116.

Calza, L., Giuliani, A., Fernandez, M., Pirondi, S., D'Intino, G., Aloe, L. and Giardino, L. (2003). Neural stem cells and cholinergic neurons: Regulation by immunolesion and treatment with mitogens, retinoic acid, and nerve growth factor. Proceedings of National Academy of Science USA. 100(12): 7325-7330.

Cárdenas-Aguayo M.delC., Silva-Lucero, M.delC., Cortes-Ortiz, M., Jiménez-Ramos, B., GómezVirgilio, L., Ramírez-Rodríguez, G., VeraArroyo, E., Fiorentino-Pérez, R., García, U., Luna-Muñoz, J. and Meraz-Ríos, M.A. (2014). Physiological Role of Amyloid Beta in Neural Cells: The Cellular Trophic Activity In Heinbockel $\mathrm{T}$ eds. Neurochemistry. Doi: $10.5772 / 57398$.

Cattoretti, G,. Buttner, M., Shaknovich, R., Kremmer, E., Alobeid, B. and Niedobitek, G. (2006). Nuclear and cytoplasmic AID in extrafollicular and germinal center B cells. Blood. 107: 39673675.

Chen, Q. and Ross, A.C. (2005). Vitamin A and immune function: retinoic acidmodulates population dynamics in antigen receptor and CD38-stimulated splenic B cells. Proceedings of the National Academy of Science USA. 102: 14142-14149.

Chen, Q. and Ross, A.C. (2007). Retinoic acid promotes mouse splenic B cell surface $\operatorname{IgG}$ expression and maturation stimulated by CD40 and IL-4. Cell Immunology. 249:37-45. 
Christov, K. (2009). The novel RAR beta isoform (beta5) is a potential target of retinoids in brest cancer. Current Cancer Drug Targets. 9:142-147.

Chytil, F. (1982). Liver and cellular vitamin binding proteins. Herpatology. 2: 282-287.

Chytil, F. and Ong, D.E. (1978). Cellular vitamin A binding proteins. Vitamins \& Hormones. 36: 132.

Conaway, H.H., Henning, P. and Lerner, U.H. (2013). Vitamin a metabolism, action, and role in skeletal homeostasis. Endocrine Reviews. 34: 766-797.

D’Ambrosio, D.N., Clugston, R.D. and Blaner, W.S. (2011). Vitamin A metabolism: an update. Nutrients. 3: 63-103.

Dawson, H.D., Collins, G., Pyle, R., Key, M., Weeraratna, A., Deep-Dixit, V., Nadal, C.N. and Taub, D.D. (2006). Direct and indirect effects of retinoic acid on human $\mathrm{Th} 2$ cytokine and chemokine expression by human $\mathrm{T}$ lymphocytes. BioMed Central Immunology. 7: 27.

Duester, G. (2008). Retinoic Acid Synthesis and Signaling during Early Organogenesis. Cell. 134(2): 921-931.

Dupe, V., Matt, N., Garnier, J.M., Chambon, P., Mark, M. and Ghyselinck, N.B. (2003). A newborn lethal defect due to inactivation of retinaldehyde dehydrogenase type 3 is prevented by maternal retinoic acid treatment. Proceedings of the National Academy of Science USA. 100: 14036-14041.

During, A. and Harrison, E.H. (2007) Mechanisms of provitamin A (carotenoid) and vitamin A (retinol) transport into and out of intestinal Caco-2 cells. Journal of Lipid Research. 48: 2283-2294.

Eichele, G. (1997). Retinoids: from hindbrain patterning to Parkinson disease. Trends in Genetics. 13:343-345.

Farooqui, A.A., Antony, P., Ong, W.Y., Horrocks, L.A. and Freysz, L. (2004). Retinoic acid mediated phospholipase A2 signaling in the nucleus. Brain Research Reviews. 45(3):179-95.

Fassbender, K., Simons, M., Bergmann, C., Stroick, M., Lutjohann, D., Keller, P., Run, H., Kuhl, S., Bertsch, T., von Bergmann, K., Hennerici, M., Beyreuther, K. and Hartmann, T. (2001). Simvastatin strongly reduces levels of Alzheimer's disease beta -amyloid peptides A beta 42 and A beta 40 in vitro and in vivo. Proceedings of National Academy of Science USA. 98: 5856-5861.

Fell, H.B. and Mellanby, E. (1953). Metaplasia produced in cultures of chick ectoderm by high vitamin A. Journal of Physiology. 43: 3034-40.

Feng, X.H. and Derynck, R. (2005). Specificity and versatility in tgf-beta signaling through Smads. Annu Rev Cell. Developmental Biology. 21: 659693.

Glass, C.K. and Rosenfeld, M.G. (2000). The coregulator exchange in transcriptional functions of nuclear receptors. Genes \& Development. 14: 121-141.

Goodman, D.S. (1984). Vitamin A and Retinoids In health and Diseases. The New England Journal of Medicine. 310:1023-1031.

Goodman, D.S. and Blaner, W.S. (1984) Biosynthesis, absorption, and hepatic metabolism of retinol. Sporn, MB, Roberts AB, Goodman, DS, eds. The Retinoids. Academic Press, New York, USA. Pp 1-39.

Goodman, D.S. and Olson, J.A. (1969). The conversion of all - trance - $b$ - carotene in to retinol. Methods in Enzymology. 15: 462-475.

Green, H.N. and Mellanby, E. (1928). Vitamin A as an anti-infective agent. British Medical Journal. 2: 691-696.

Green, H.N. and Mellanby, E. (1930). Carotene and vitamin A: the anti-infective action of carotene. British Journal of Experimental Pathology. 11: 81-89.

Greena, A.C., Martin, T.J. and Purton, L.E. (2016). The role of vitamin $\mathrm{A}$ and retinoic acid receptor signaling in post-natal maintenance of bone. Journal of Steroid Biochemistry and Molecular Biology. 155: 135-146.

Gudas, L.J. (2013). Retinoids induce stem cell differentiation via epigenetic changes. Seminars in Cell and Developmental Biology. 24: 701-705.

Guo, Y., Brown, C., Ortiz, C. and Noelle, R.J. (2015). Leukocyte homing, fate, and function are controlled by retinoic acid. Physiological Reviews. 95: 125-148.

Harrison, E.H. (2012). Mechanisms involved in the intestinal absorption of dietary vitamin A and provitamin A carotenoids. Biochimica et Biophysica Acta. 1821: 70-77.

Henke, E., Perk, J., Vider, J., de-Candia, P., Chin, Y., Solit, D.B., Ponomarev, V., Cartegni, L., Manova, K., Rosen, N. and Benezra, R. (2008). Peptide-conjugated antisense oligonucleotides for targeted inhibition of a transcriptional regulator in vivo. National Biotechnology. 26: 91-100.

Holst, A., Lefcort, F. and Rohrer, H. (1997). TrkA expression levels of sympathetic neurons correlate with NGF-dependent survival during development and after treatment with retinoic acid. European Journal of Neuroscience. 9: 2169-2177.

Hong, C.S., Carmile, L., Nomata, Y., Mori, H., Bredesen, D.E. and Koo, E.H. (1999). Contrasting role of presenilin-1 and presenilin-2 in neuronal differentiation in vitro. Journal of Neuroscience. 19: 637-643.

Hung, A.Y., Koo, E.H., Haass, C. and Selkoe, D.J. (1992). Increased expression of beta amyloids precursor protein during neuronal differentiation is not accompanied by secretory cleavage. Proceedings of National Academy of Science USA. 89: 9439-9443. 
Iavarone, A. and Lasorella, A. (2006). ID proteins as targets in cancer and tools in neurobiology. Trends in Molecular Medicine. 12: 588-594.

Imdad, A., Herzer, K., Mayo-Wilson, E., Yakoob, M.Y. and Bhutta, Z.A. (2010). Vitamin A supplementation for preventing morbidity and mortality in children from 6 months to 5 years of age. Cochrane Database Systematic Reviews. Doi: 10.1002/14651858.

Isken, A., Golczak, Oberhauser, V., Hunzelmann, S., Driever, W., Imanishi, Y., Palczewski, K. and von-Lintig, J. (2008). RBP4 disrupts vitamin A uptake homeostasis in a STRA6-deficient animal model for Matthew-Wood syndrome. Cell Metabolism. 7: 258-268.

Isler, O., Hubere, W., Ronco, A. and Kofler, M. (1947). Synthesis des Vitamin A. Helvetica Chimica Acta. 30: 1911-1927.

Jeffrey, R., Peterson, R.V. and Sharma, R.L. (2006). Davisson Reactive oxygen species in the neuropathogenesis of hypertension. Current Hypertension Reports. 8(3): 232-241.

Kadigamuwa, C.C., Le, V.Q. and Wimalasena, K. (2015) 2, 2'- and 4, 4'-Cyanines are transporterindependent in vitro dopaminergic toxins with the specificity and mechanism of toxicity similar to $\mathrm{MPP}^{+}$. Journal of Neurochemistry. 135(4): $755-767$.

Kanai, M., Raz, A. and Goodman, D.S. (1968). Retinol Binding protein: the transport protein for Vitamin A in human plasma. Journal of Clinical Investigation. 47: 2025-2044.

Kasinski, A.L. and Slack, F.J. (2011). MicroRNAs en route to the clinic: progress in validating and targeting microRNAs for cancer therapy. Nature Reviews Cancer. 11:849-864.

Kawaguchi, R., Yu, J., Honda, J., Hu, J., Whitelegge, J., Ping, P., Wiita, P., Bok, D. and Sun, H.A. (2007). Membrane receptor for retinol binding protein mediates cellular uptake of vitamin A. Science. 315: 820-825.

Kernie, S.G., Erwin, T.M. and Parada, L.F. (2001). Brain remodeling due to neuronal and astrocytic proliferation after controlled cortical injury in mice. Journal of Neuroscience Research. 66: 317-326.

Kikuchi, K., Holdwa, J.E., Major, R.J., Blum, N., Dahn, R.D., Begemann, G. and Poss, K.D. (2011). Retinoic acid production by endocardium and epicardium is an injury response essential for zebrafish heart regeneration. Developmental Cell. 20: $397-404$.

Kiningham, K.K., Cardozo, Z.A., Cook, C., Cole, M.P., Stewart, J.C., Tassone, M., Coleman, M.C., Spitz ,D.R. (2008). All- trance retinoic acid induce manganese superoxide dismutase in human neruroblastma throunfg NF-кB. Free Radical Biology and Medicine. 44: 1610-1616.

Koldamova, R.P., Lefterov, I.M., Ikonomovic, M.D., Skoko, J., Lefterov, P.I., Isanski,
B.A., DeKosky, S.T. and Lazo, J.S. (2003). 22RHydroxycholesterol and 9-cis-Retinoic Acid Induce ATP-binding Cassette Transporter A1 Expression and Cholesterol Efflux in Brain Cells and Decrease Amyloid $\beta$ Secretion. The Journal of Biological Chemistry. 278: 13244-13256.

Koryakina, A., Aeberhard, J., Kiefer, S., Hamburger, M., Kuenzi, P. (2009). Regulation of secretase by all- trance-retinoic acid. FEBS Journal. 276: 2645-2655.

Laneve, P., Di-Marcotullio, L., Gioia, U., Fiori, M.E., Ferretti, E., Gulino, A., Bozzoni, I. and Caffarelli, E. (2007). The interplay between microRNAs and the neurotrophin receptor tropomyosinrelated kinase C controls proliferation of human neuroblastoma cells. Proceedings of National Academy of Science USA. 104: 7957-7962.

Laneve, P., Gioia, U., Andriotto, A., Moretti, F., Bozzoni, I. and Caffarelli, E. (2010). A minicircuitry involving REST and CREB controls miR-9-2 expression during human neuronal differentiation. Nucleic Acids Research. 38: 6895-6905.

Lasorella, A. and Iavarone, A. (2006) The protein ENH is a cytoplasmic sequestration factor for Id2 in normal and tumor cells from the nervous system. Proceedings of the National Academy of Science USA. 103: 4976-4981.

Lee, H., Casadesus, G., Zhu, X., Lee, H., Perry, G., Smith, M.A., Gustaw-Rothenberg, K. and Lerner, A. (2009). All- Trance Retinoic Acids as a novel therapeutic strategy for Alzheimer's disease. Expert Review of Neurotherapeutics. 9(11): 1615-1621.

Leuner, K., Schütt, T., Kurz, C., Eckert, S.H., Schiller, Occhipinti, A., Mai, S., Jendrach, M., Eckert, G.P., Kruse, S.E., Palmiter, R.D., Brandt, U., Dröse, S., Wittig, I., Willem, M., Haass, C., Reichert, A.S. and Müller, W.E. (2012). Mitochondrion-Derived Reactive Oxygen Species Lead to Enhanced Amyloid Beta Formation. Antioxidants \& Redox Signaling. 16(12): 14211433.

Lo'pez-Carballo, G., Moreno, L., Masia, S., Pe'rez, P. and Barettino, D. (2002). Activation of the Phosphatidylinositol 3-Kinase/Akt Signaling Pathway by Retinoic Acid Is Required for Neural Differentiation of SH-SY5Y Human Neuroblastoma Cells. The Journal of Biological Chemistry. 277(28): 25297-25304.

Lobo, G.P., Hessel, S., Eichinger, A., Noy, N., Moise, A.R., Wyss, A., Palczewski, K. and Von-Lintig, J. (2010). ISX is a retinoic acid-sensitive gatekeeper that controls intestinal $\beta, \beta$-carotene absorption and vitamin A production. FASEB Journal. 24: 1656-1666.

Ma, Y., Chen, Q. and Ross, A.C. (2005). Retinoic acid and polyriboinosinic:polyribocytidylic acid stimulate robust anti-tetanus antibody production while differentially regulating type 1/type 2 
cytokines and lymphocyte populations. Journal of Immunology. 174:7961-7969.

Martinsen, B.J. and Bronner-Fraser, M. (1998). Neural crest specification regulated by the helixloop-helix repressor Id2. Science. 281: 988-991.

Maruyama, H., Kleeff, J., Wildi, S., Friess, H., Büchler, M.W., Israel, M.A. and Korc, M. (1999). Id-1 and Id-2 Are Overexpressed in Pancreatic Cancer and in Dysplastic Lesions in Chronic Pancreatitis. American Journal of Pathology. 155(3): 815-822.

Mathew, L.K., Sengupta, S.S., Franzosa, J., Perry, J., La-Du, J., Andreasen, E.A. and Tanguay, R.L. (2009). Comparative expression profiling reveals an essential role for Raldh2 in epimorphic regeneration. Journal of Biological Chemistry. 284: 33642-33653.

McCollum, E.V. and Davis, M. (1913). The necessity of certain lipids in the diet during growth. Journal of Biological Chemistry. 15: 167-75.

MCLaren, D.S. (1981). The luxus Vitamins -A and B12. American Journal of Clinical Nutrition. 34: $1611-1616$.

Miners, J.S., Barua, N., Kehoe, P.G., Gill, S. and Love, S. (2011). A $\beta$-degrading enzymes: potential for treatment of Alzheimer disease. Journal of Neuropathology and Experimental Neurology. 70(11): 944-959.

Molotkov, A., Fan, X. and Duester, G. (2002). Excessive vitamin A toxicity in mice genetically deficient in either alcohol dehydrogenase Adh1 or Adh3. European Journal of Biochemistry. 269: 2607-2612.

Molotkov, A., Molotkova, N. and Duester, G. (2006). Retinoic acid guides eye morphogenetic movements via paracrine signaling but is unnecessary for retinal dorsoventral patterning. Development. 133: 1901-1910.

Morishima, Y., Gotoh, Y., Zieg, J., Barrett, T., Takano, H., Flavell, R., Davis, R.J., Shirasaki, Y. and Greenberg, M.E. (2001). $\beta$-Amyloid Induces Neuronal Apoptosis Via a Mechanism that Involves the c-Jun N-Terminal Kinase Pathway and the Induction of Fas Ligand. The Journal of Neuroscience. 21(19): 7551-7560.

Mytilineou, C., Kramer, B.C., Yabut, J.A. (2002). Glutathione depletion and oxidative stress. Parkinsonism \& Related Disorders. 8(6): 385387.

Nalivaeva, N.N., Beckett, C., Belyaev, N.D. and Turner, A.J. (2012a). Are amyloid-degrading enzymes viable therapeutic targetsin Alzheimer's disease?. Journal of Neurochemistry. 120(1): 167-185.

Nalivaeva, N.N., Belyaev, N.D., Zhuravin, I.A., Turner, A.J. (2012b). The Alzheimer's AmyloidDegrading Peptidase, Neprilysin:Can We Control It?. International Journal of Alzheimer's Disease. Doi: 10.1155/2012/383796.
Nalivaeva, N.N., Fisk, L.R., Belyaev, N.D. and Turner, A.J. (2008). Amyloid-degrading enzymes as therapeutic targets in Alzheimer's disease. Current Alzheimer Research 5(2): 212-224.

Niederreither, K. and Dolle, P. (2008). Retinoic acid in development: towards an integrated view. Nature Review Genetics. 9: 541-553.

O’Byrne, S.M., Wongsiriroj, N., Libien, J., Vogel, S., Goldberg, I., Baehr, W., Palczewski, K. and Blaner, W.S, (2005). Retinoid absorption and storage is impaired in mice lacking lecithin: retinol acyltransferase (LRAT). Journal of Biological Chemistry. 280: 35647-35657.

Perissi, V., Jepsen, K., Glass, C.K. and Rosenfeld, M.G. (2010). Deconstructing repression: evolving models of co-repressor action. Nature Reviews Genetics. 11: 109-123.

Perk, J., Iavarone, A. and Benezra, R. (2005). Id family of helix-loop-helix proteins in cancer. Nature Reviews Cancer. 5: 603-614.

Petty, W.J., Li, N. and Biddle, A. (2005). A novel retinoid acid receptor beta isoform and retinoid acid receptor beta isoform and retinoid resistance in lung carcinogenesis. Journal of National Cancer Institute. 97: 1645-1651.

Poole, A.R., Dingel, J.T., Mallia, A.K. and Goodman, D.S. (1975). The localization of Retinol binding protein in rat liver by immunofluorescence Microscopy. Journal of cell Science. 19: 379-94.

Quadro, L., Hamberger, L., Gottesman, M.E., Wang, F., Colantuoni, V., Blaner, W.S., Mendelsohn, C.L. (2005). Pathways of vitamin A delivery to the embryo: insights from a new tunable model of embryonic vitamin A deficiency. Endocrinology. 146(10): 4479-4490.

Rahman, K. (2007). Studies on free radicals, antioxidants, and co-factors. Clinical Interventions in Aging 2(2): 219-236.

Rochette-Egly, C. (2015). Retinoic acid signaling and mouse embryonic stem cell differentiation: cross talk between genomic and non-genomic effects of RA. Biochimica Biophysica Acta. 1851: 66-75.

Ross, A.C. (2012). Vitamin A and retinoic acid in T cell-related immunity. American Journal of Clinical Nutrition. 96: 1166S-1172S.

Ruzinova, M.B. and Benezra, R. (2003). Id proteins in development, cell cycle and cancer. Trends in Cell Biology. 13: 410-418

Saari, J.C., Bredberg, L. and Garwin, G.G. (1982). Identification of endogenous retinoids associated with three cellular retinoi-binding proteins from bovine retina and retinal pigments. Journal of Biological Chemistry. 257: 13329-13333.

Satoh, J. and Kurod, Y. (2000) Amyloid precursor proteins beta- secretase (BACE) $m$ RNA expression in human neural cell lines following induction of neuronal differentiation and exposure to cytokines and growth factors. Neuropathology. 20: 289-296. 
Schoenherr, C.J. and Anderson, D.J. (1995). The neuron-restrictive silencer factor (NRSF): a coordinate repressor of multiple neuron-specific genes. Science. 267: 1360-1363.

Shenga, N., Xiea, Z., Wanga, C., Baia, G., Zhanga, K., Zhua, Q., Songa, J., Guillemotb, F., Chenc, Y., Lina, A. and Jing, N. (2010). Retinoic acid regulates bone morphogenic proteinsignal duration by promoting the degradation of phosphorylated Smad1. . Proceedings of the National Academy of Science USA. 107: 1888618891.

Smith, M.A. (1998) Alzheimer disease. International Review of Neurobiology. 42:1 -54.

Smith, M.A. (2006). Oxidative stress and iron imbalance in Alzheimer disease: how rust become the fuss!. Journal of Alzheimers Disease. 9: 305-308.

Sonnen, J.A., Larson, E.B., Gary, S.L., Wilson, A., Kohama, S.G., Crane, P.K., Breitner, J.C. and Montine, T.J. (2009). Free radical damage to cerebral cortex in Alzheimer's disease, microvascular brain injury, and smoking. Annual Neurology. 65: 121-123.

Stephensen, C.B., Moldoveanu, Z. and Gangopadhyay, N.N. (1996). Vitamin A deficiency diminishes the salivary immunoglobulin A response and enhances the serum immunoglobulin $G$ response to influenza A virus infection in BALB/c mice. Journal of Nutrition. 126: 94-102.

Tasi, F.M., Shyu, R.Y., Lin, S.C., Wu, C.C. and Jiang, S.Y. (2009). Induction of apoptosis by the retinoid inducible growth regulator RIGI depends on the NC motif in HtTA cervical cancer cells. BMC cell Biology. 10: 15.

Turner, P.R., Conner, K.O., Fate, W.P. and Abraham, W.C. (2003). Roles of amyloid precursor protein and its fragments in regulating neural activity, Plasticity and Memory. Progress in Neurobiology. 70: 1-32.

Twining, S.S., Schulte, D.P., Wilson, P.M., Fish, B.L. and Moulder, J.E. (1997). Vitamin A deficiency alters rat neutrophil function. Journal of Nutrition. 127: 558-565.

Van-Bennekum, A., Werder, M., Thuahnai., S.T., Han, C.H., Duong, P., Williams, D.L., Wettstein, P., Schulthess, G., Phillips, M.C. and Hauser, H. (2005). Class B scavenger receptor-mediated intestinal absorption of dietary $\beta$-carotene and cholesterol. Biochemistry. 44: 4517-4525.

Vandeputte, D.A., Troost, D., Leenstra, S., IjlstKeizers, H., Ramkema,. M, Bosch, D.A., Baas, F., Das, N.K. and Aronica, E. (2002). Expression and distribution of id helix-loop-helix proteins in human astrocytic tumors. Glia. 38: 329-338.
Vogel, G. (2000). Neuroscience: new brain cells prompt new theory of depression. Science 290: 258-259.

Wahrle, S., Das, P., Nyborg, A.C., McLendon, C., Shoji, M., Kawarabayashi, T., Younkin, L.H., Youkin, S.G. and Golde, T.E (2002). Cholesteroldependent gamma-secretase activity in buoyant cholesterol-rich membrane microdomains. Neurobiology of Disease. 9: 11-23.

Wang, M., Jin, H., Tang, D., Huang, S., Zuscik, M.J. and Chen, D. (2011). Smad1 plays an essential role in bone development and postnatal bone formation. Osteoarthritis Cartilage. 19(6): 751762.

Waring, P. and Müllbacher, A. (1999). Cell death induced by the Fas/Fas ligand pathway and its role in pathology. Immunology and Cell Biology. 77: 312-317.

Wisse, E., de Zanger, R.B., van-der-Smissen, P. and McCuskey, R.S. (1985). The liver sieve: considerations concerning the structure and function of endothelial fenestrae, the sinusoidal wall and the space of disse. Hepatology. 5: 683692.

Wuarin, L. and Sidell, N. (1991). Differential susceptibilities of spinal cord neurons to retinoic acid-induced survival and differentiation. Developmental Biology. 144:429-435.

Wuarin, L., Sidell, N. and De Vellis, J. (1990). Retinoids increase perinatal spinal cord neuronal survival and astroglial differentiation. International Journal of Developmental Neuroscience. 8: 317-326.

Zakany, J., Kmita, M. and Duboule, D. (2004). A Dual Role for Hox Genes in Limb AnteriorPosterior Asymmetry. Science. 304: 1669-1672.

Zanotto- Filho. A., Schroder, R. and Moreira, J.C. (2008). Xanthine oxidase- dependent ROS production mediates vitamin A pro- oxidant effects in cultured Sertoli cells. Free Radical Research. 42: 593-601.

Zhang, C., Zhang, Z., Shu, H., Liu, S., Song, Y., Qiu, K. and Yang, H. (2010). The modulatory effects of bHLH transcription factors with the Wnt/betacatenin pathway on differentiation of neural progenitor cells derived from neonatal mouse anterior subventricular zone. Brain Research. 1315: 1-10.

Zhao, Z. and Ross, A.C. (1995). Retinoic acid repletion restores the number of leukocytes and their subsets and stimulates natural cytotoxicity in vitamin A-deficient rats. Journal of Nutrition. 125: 2064-2073.

Zhelyaznik, N., Schrage, K., McCaffery, P. and Mey, J. (2003). Activation of retinoic acid signaling after sciatic nerve injury: up regulation of cellular retinoid binding proteins. European Journal of Neuroscience. 18: 1033-1040. 